\title{
Degradation leads to dramatic decrease in topsoil but not subsoil root biomass in an alpine meadow on the Tibetan Plateau, China
}

\author{
ZHANG Zhenchao $^{1,2}$, LIU Miao ${ }^{1,3}$, SUN Jian $^{1 *}$, WEI Tianxing ${ }^{4}$ \\ ${ }^{1}$ Synthesis Research Centre of Chinese Ecosystem Research Network, Key Laboratory of Ecosystem Network Observation and \\ Modelling, Institute of Geographic Sciences and Natural Resources Research, Chinese Academy of Sciences, Beijing 100101, \\ China; \\ ${ }^{2}$ State Key Laboratory of Soil Erosion and Dryland Farming on the Loess Plateau, Institute of Soil and Water Conservation, \\ Northwest A\&F University, Yangling 712100, China; \\ ${ }^{3}$ Arid Land Research Center, Tottori University, Tottori 6800001, Japan; \\ ${ }^{4}$ School of Soil and Water Conservation, Beijing Forestry University, Beijing 100083, China
}

\begin{abstract}
Understanding the effects of degradation on belowground biomass (BGB) is essential for assessment of carbon budget of the alpine meadow ecosystem on the Tibetan Plateau, China. This ecosystem has been undergoing serious degradation owing to climate change and anthropogenic activities. This study examined the response of the vertical distribution of plant BGB to degradation and explored the underlying mechanisms in an alpine meadow on the Tibetan Plateau. A field survey was conducted in an alpine meadow with seven sequential degrees of degradation in the Zoige Plateau on the Tibetan Plateau during the peak growing season of 2018. We measured aboveground biomass (AGB), BGB, soil water content (SWC), soil bulk density (SBD), soil compaction (SCOM), soil organic carbon (SOC), soil total nitrogen (STN), soil total phosphorus (STP), soil available nitrogen (SAN), and soil available phosphorus (STP) in the $0-30 \mathrm{~cm}$ soil layers. Our results show that degradation dramatically decreased the $\mathrm{BGB}$ in the $0-10 \mathrm{~cm}$ soil layer $\left(\mathrm{BGB}_{0-10}\right)$ but slightly increased the subsoil $\mathrm{BGB}$. The main reason may be that the physical-chemical properties of surface soil were more sensitive to degradation than those of subsoil, as indicated by the remarked positive associations of the trade-off value of $\mathrm{BGB}_{0-10}$ with SWC, SCOM, SOC, STN, SAN, and STP, as well as the negative correlation between the trade-off value of $\mathrm{BGB}_{0-10}$ and $\mathrm{SBD}$ in the soil layer of $0-10 \mathrm{~cm}$. In addition, an increase in the proportion of forbs with increasing degradation degree directly affected the $\mathrm{BGB}$ vertical distribution. The findings suggest that the decrease in the trade-off value of $\mathrm{BGB}_{0-10}$ in response to degradation might be an adaptive strategy for the degradation-induced drought and infertile soil conditions. This study can provide theoretical support for assessing the effects of degradation on the carbon budget and sustainable development in the alpine meadow ecosystem on the Tibetan Plateau as well as other similar ecosystems in the world.
\end{abstract}

Keywords: belowground biomass; soil properties; plant community structure; degradation; alpine meadow; Tibetan Plateau

Citation: ZHANG Zhenchao, LIU Miao, SUN Jian, WEI Tianxing. 2020. Degradation leads to dramatic decrease in topsoil but not subsoil root biomass in an alpine meadow on the Tibetan Plateau, China. Journal of Arid Land, 12(5): 806-818. https://doi.org/10.1007/s40333-020-0074-x

\footnotetext{
*Corresponding author: SUN Jian (E-mail: sunjian@igsnrr.ac.cn)

Received 2020-03-12; revised 2020-07-02; accepted 2020-08-14

C Xinjiang Institute of Ecology and Geography, Chinese Academy of Sciences, Science Press and Springer-Verlag GmbH Germany, part of Springer Nature 2020
} 


\section{Introduction}

Grasslands occupy over $25 \%$ of the Earth's terrestrial surface and store approximately $30 \%$ of the global terrestrial carbon (C) pool (Hewins et al., 2015). Soil C sequestration in grasslands occurs at an estimated rate of $0.5 \mathrm{Pg} \mathrm{C} / \mathrm{a}$ globally and accounts for approximately a quarter of the world's potentially sequestered soils (Qiu et al., 2013). The Tibetan Plateau, approximately $35 \%$ of which is occupied by alpine meadows (Zheng et al., 2000), is equal to about $44 \%$ of China's total grasslands and approximately 6\% of grasslands worldwide (Piao et al., 2012). Alpine grasslands are vital to local livestock husbandry development and ecological functions, including soil and water conservation, biodiversity maintenance, and C sequestration ( $\mathrm{Li}$ et al., 2013; Qin et al., 2018). However, this region's grasslands are very fragile owing to the unique climate and harsh environmental conditions (Sun and Wang, 2016; Sun et al., 2019a). These grasslands have undergone serious degradation under the influence of climate change and anthropogenic activities (Harris, 2010; Sun et al., 2014; Dong et al., 2020), greatly threatening local economic development and ecological security (Huo et al., 2013).

As a main source of the soil $\mathrm{C}$ pool and plant $\mathrm{C}$ stock, belowground biomass (BGB) plays an important role in the $\mathrm{C}$ cycles of terrestrial ecosystems (Mokany et al., 2010; Sun et al., 2013), especially in grassland ecosystems where over $25 \%$ of the plant $\mathrm{C}$ is stored in roots ( $\mathrm{Li}$ et al., 2008; Yang et al., 2009). On the Tibetan Plateau, where BGB constitutes the core portion of the grassland's total primary productivity (Li et al., 2011), the root-to-shoot ratio can be as high as 5.8 (Yang et al., 2009). The alpine grassland ecosystem of the Tibetan Plateau is currently considered a C sink (Yang et al., 2008), largely because the roots account for a notably great proportion of alpine plants (Wu et al., 2011). Therefore, it is important to precisely estimate the root biomass and turnover rate to obtain a more reliable scientific assessment of the $\mathrm{C}$ budget in this terrestrial ecosystem. However, because of methodological difficulties and high cost, the distribution and transfer of a plant's BGB in response to grassland degradation is not well understood (Sun et al., 2018a).

Roots serve as both the primary pathways for a plant's nutrient and water uptake (Wu et al., 2011) and its anchorage to the basement soil. As they consume resources, roots are involved in underground competition with other plants (Hortal et al., 2017), complex mutualistic relationships with beneficial bacteria and fungi (Duran et al., 2018), and competitive correlations with detrimental microbes (Rey and Schornack, 2013). The root system's overall structure and ability to adapt to habitat conditions is called plasticity and is a crucial determinant of the overall plant adaptability (Gruber et al., 2013; Rogers and Benfey, 2015). For example, the roots of perennial plants in particular legumes can affect the physical properties of forcefully compacted soils (Gląb and Szewczyk, 2014). Because they enhance the water retention properties, these types of roots can be used to regenerate soils that have undergone physical degradation. However, some species have different effects on the soil environment, owing mainly to their unique root morphologies (Silva et al., 2014). In addition, root systems affect plant growth through nutrient foraging, gaseous exchange, and absorption of beneficial microorganisms (Pieterse et al., 2014; Verbon and Liberman, 2016).

The main properties of the root system are as follows: length, biomass, volume, anatomy, and surface area (Lynch and Brown, 2012). These characteristics facilitate the ability of plants to survive under various biological and abiotic stresses, including salinity, extreme temperatures, waterlogging, drought, and nutrient deficiency (Dukes et al., 2005; Rodrigues et al., 2015). Thus, roots are considered to be an important factor determining the competitive ability of individual plants under environmental stress, which affects the responses of the plant community structure to environmental changes (Haichar et al., 2008). The characteristics and morphology of grass roots are closely linked to environmental conditions, and these roots tend to have highly dynamic lifespans ranging from a few days to weeks (Tingey et al., 2010). In addition, previous researches have revealed that the distribution of plant root biomass can be affected by various environmental factors, including soil physical-chemical and biological properties, climatic conditions, and plant characteristics (Rodriguez et al., 2007; Macinnis-Ng et al., 2010; Li et al., 2011). For instance, Zhang et al. (2019) found that plants allocate more root biomass to deeper soils for maintaining plant water acquisition and growth in response to drought stress. As grassland degradation 
induces dynamics in the soil water, nutrients, microenvironment, and plant properties, the BGB distribution patterns might also fluctuate during degradation. There is little available information on the variation of the direction and magnitude of BGB distribution patterns in response to degradation of alpine meadows. We hypothesized that BGB in topsoil but not subsoil may be more vulnerable to degradation because surface soil loses water and nutrients relatively quickly compared with subsoil.

In this study, we examined variations in BGB distribution patterns along degradation gradients in an alpine meadow on the Tibetan Plateau of China. The aims of the study were: (i) to verify our hypothesis on the BGB dynamics at different soil depths in response to grassland degradation; and (ii) to explore the underlying mechanisms driving the changes in BGB vertical distribution in a degraded alpine meadow. Our results may offer insights into grassland degradation and, more specifically, the effects of degradation on the $\mathrm{C}$ budget of the alpine meadow ecosystem.

\section{Materials and methods}

\subsection{Study area}

The study was conducted in an alpine meadow at the Zoige Plateau $\left(32^{\circ} 20^{\prime}-34^{\circ} 00^{\prime} \mathrm{N}, 101^{\circ} 30^{\prime}-\right.$ $103^{\circ} 30^{\prime} \mathrm{E}$ ), which is located in the northeastern part of the Tibetan Plateau of China (Fig. 1). The Zoige Plateau has an average altitude of $3500 \mathrm{~m}$ and covers an area of $6180 \mathrm{~km}^{2}$ (Liu et al., 2020a). The climate is characterized as cold and humid. The mean temperature during the year, in the hottest month (July), and in the coldest month (January) is $1.5^{\circ} \mathrm{C}, 11.1^{\circ} \mathrm{C}$, and $-9.7^{\circ} \mathrm{C}$, respectively (Liu et al., 2020b). The mean annual precipitation is approximately $700-800 \mathrm{~mm}$; most precipitation occurs from May to August (Liu et al., 2020a). The plant community at our study site is dominated by Kobresia tibetica, Stipa capillata, and Carex lasiocarpa (Liu et al., 2020b). The soils are classified mainly as Cambisols using the World Reference Base for Soil Resources (WRB) soil classification system and as Inceptisols using the United States Department of Agriculture (USDA) soil taxonomy (Liu et al., 2020a).

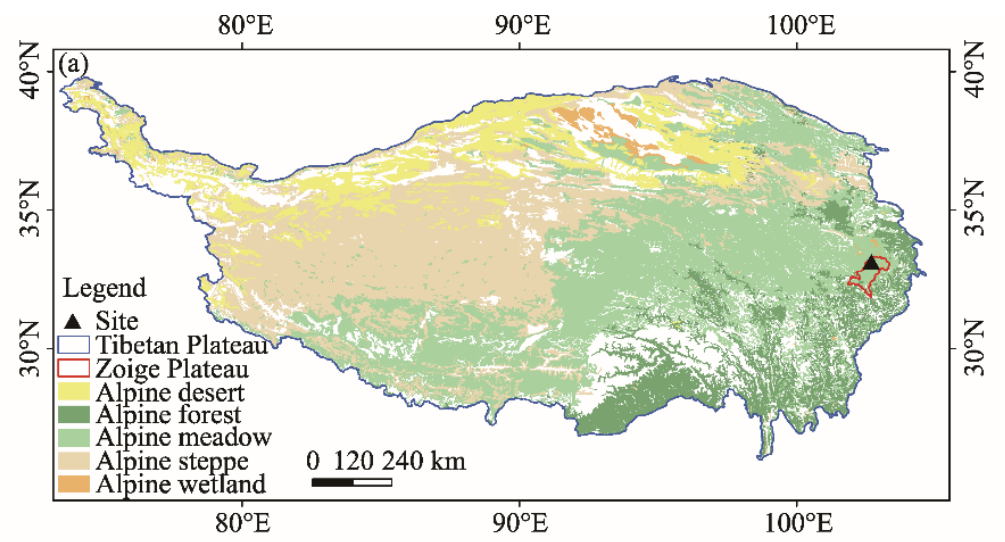

(b)

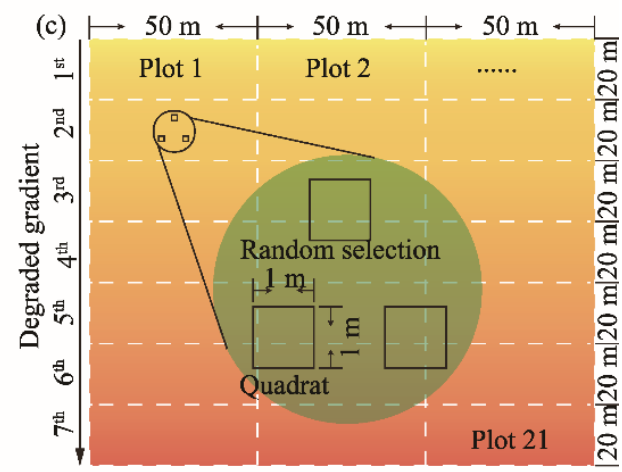

Fig. 1 Location of sampling site at the Zoige Plateau on the Tibetan Plateau of China (a), photograph showing the landscape of sampling site (b), and schematic illustration of experimental design (c) 


\subsection{Experimental design and soil sampling}

We sampled nine degraded grasslands and chose seven sequential degradation gradients according to the vegetation coverage and plant community structure, which is a common method of classifying degradation in this type of study (Ma et al., 2002; Zhang et al., 2019; Liu et al., 2020a). All these grasslands were freely grazed; the livestock was mainly yaks and horses, which contributed greatly to the degradation. Table 1 displays detailed information on the seven degradation gradients, which were adjacent and thus had similar topography and environmental status; the heterogeneity within a degradation gradient was relatively low. The sampling survey was carried out in August (the peak growing season) 2018. We selected three representative sampling plots which were approximately $50 \mathrm{~m} \times 20 \mathrm{~m}$ as replicates on each degradation gradient. Next, three quadrats $(1 \mathrm{~m} \times 1 \mathrm{~m})$ within each sampling plot were randomly selected to obtain plant and soil samples for measuring their characteristics. The plant species were recorded, and the soil compaction (SCOM) was determined via a portable time-domain reflectometry equipment (TDR 100, Spectrum Technologies Inc., Chicago, IL, USA).

Table 1 Information on the seven degradation gradients

\begin{tabular}{|c|c|c|c|c|}
\hline $\begin{array}{c}\text { Degradation } \\
\text { gradient }\end{array}$ & Coordinates & Altitude (m) & Main species & Coverage $(\%)$ \\
\hline $1^{\text {st }}$ & $\begin{array}{c}33^{\circ} 13^{\prime} 37.53^{\prime \prime} \mathrm{N} \\
102^{\circ} 36^{\prime} 51.26^{\prime \prime} \mathrm{E}\end{array}$ & 3678 & Stipa capillata, Carex tristachya & $89.00 \pm 5.13$ \\
\hline $2^{\text {nd }}$ & $\begin{array}{c}33^{\circ} 13^{\prime} 37.44^{\prime \prime} \mathrm{N} \\
102^{\circ} 36^{\prime} 51.69^{\prime \prime} \mathrm{E}\end{array}$ & 3695 & Stipa capillata, Anaphalis sinica & $78.00 \pm 3.26$ \\
\hline $3^{\text {rd }}$ & $\begin{array}{c}33^{\circ} 13^{\prime} 37.11^{\prime \prime} \mathrm{N} \\
102^{\circ} 36^{\prime} 50.87^{\prime \prime} \mathrm{E}\end{array}$ & 3702 & Stipa capillata, Carex tristachya & $67.00 \pm 4.15$ \\
\hline $4^{\text {th }}$ & $\begin{array}{l}33^{\circ} 13^{\prime} 36.93^{\prime \prime} \mathrm{N} \\
102^{\circ} 36^{\prime} 51.46^{\prime \prime} \mathrm{E}\end{array}$ & 3721 & Carex tristachya, Stipa capillata & $50.00 \pm 4.71$ \\
\hline $5^{\text {th }}$ & $\begin{array}{l}33^{\circ} 13^{\prime} 37.84^{\prime \prime} \mathrm{N} \\
102^{\circ} 36^{\prime} 51.11^{\prime \prime} \mathrm{E}\end{array}$ & 3725 & Carex tristachya, Artemisia desertorum & $38.00 \pm 3.52$ \\
\hline $6^{\text {th }}$ & $\begin{array}{l}33^{\circ} 13^{\prime} 37.62^{\prime \prime} \mathrm{N} \\
102^{\circ} 36^{\prime} 50.97^{\prime \prime} \mathrm{E}\end{array}$ & 3736 & Artemisia desertorum, Agrostis matsumurae & $29.00 \pm 2.20$ \\
\hline $7^{\text {th }}$ & $\begin{array}{l}33^{\circ} 13^{\prime} 37.39^{\prime \prime} \mathrm{N} \\
102^{\circ} 36^{\prime} 51.25^{\prime \prime} \mathrm{E}\end{array}$ & 3740 & Artemisia desertorum, Oxytropis kansuensis & $17.00 \pm 2.44$ \\
\hline
\end{tabular}

Note: $\operatorname{Mean} \pm$ SE.

We clipped the aboveground parts of plants by using scissors at ground level and separated them according to plant species. We also collected the belowground parts of plants in the $0-30 \mathrm{~cm}$ soil depth (0-10, 10-20, and 20-30 cm layers) by taking soil cores ( $5 \mathrm{~cm}$ in diameter), with three replicates for every layer within a quadrat. The blocks were then transported to the laboratory and soaked in water to remove the residual soil using a $0.5-\mathrm{mm}$ sieve. The plant samples were oven-dried at $65^{\circ} \mathrm{C}$ until they reached a constant weight to determine the aboveground biomass (AGB) and BGB. Soil samples were also collected from the three replicate soil profiles in the 0 $30 \mathrm{~cm}$ soil depth (0-10, 10-20, and 20-30 cm layers) using $5 \mathrm{~cm}$ diameter soil cores and $200 \mathrm{~cm}^{3}$ cutting rings. For the former (AGB), soil samples were handpicked to extract fine roots and other organic materials and were used to analyze the soil chemical properties after being air-dried and sieved through a $2.0-\mathrm{mm}$ mesh. For the latter (BGB), soil samples were oven-dried at $105^{\circ} \mathrm{C}$ until they reached a constant weight, and then the soil water content (SWC) and soil bulk density (SBD) were measured. The soil organic carbon (SOC), soil total nitrogen (STN), soil total phosphorus (STP), soil available nitrogen (SAN), and soil available phosphorus (SAP) were determined by an external heating method (the $\mathrm{K}_{2} \mathrm{Cr}_{2} \mathrm{O}_{7}$ volumetric method), a vario MACRO cube elemental analyzer (Elementar Analysensysteme $\mathrm{GmbH}$, Germany), the $\mathrm{NaHCO}_{3}$ alkali digestion method and molybdenum antimony colorimetry, the continuous alkali-hydrolyzed reduction-diffusion method, and the Olsen method, respectively (Olsen et al., 1954; Bao, 2000).

\subsection{Data analysis}

The benefit of BGB in a given soil layer is expressed as the relative deviation from the mean of an objective observation calculated via the following equation (Bradford and Damato, 2012; Sun et al., 2018b): 


$$
B_{i}=\frac{x_{i}-x_{\min }}{x_{\max }-x_{\min }},
$$

where $B_{i}$ is the magnitude of the benefit for objective $i ; x_{i}$ is the measured value of $i$; and $x_{\min }$ and $x_{\max }$ are the minimum and maximum values for all $x_{i}$, respectively. A three-dimensional trade-off method was used to describe the BGB trade-offs among the three soil layers $(0-10,10-20$, and 20-30 cm) (Li et al., 2019). The vertical distance (l) from the objective point $x$ to the zero trade-off line indicates the magnitude of the benefit of BGB in each soil layer (Fig. 2). The trade-off was decomposed into those in the $\mathrm{a}, \mathrm{b}$, and $\mathrm{c}$ directions by tracing the BGB in the soil layers of $0-10,10-20$, and 20-30 cm, respectively (Fig. 2). The trade-off components in each direction were calculated by finding the point on the zero trade-off line using the Euclidean distance.

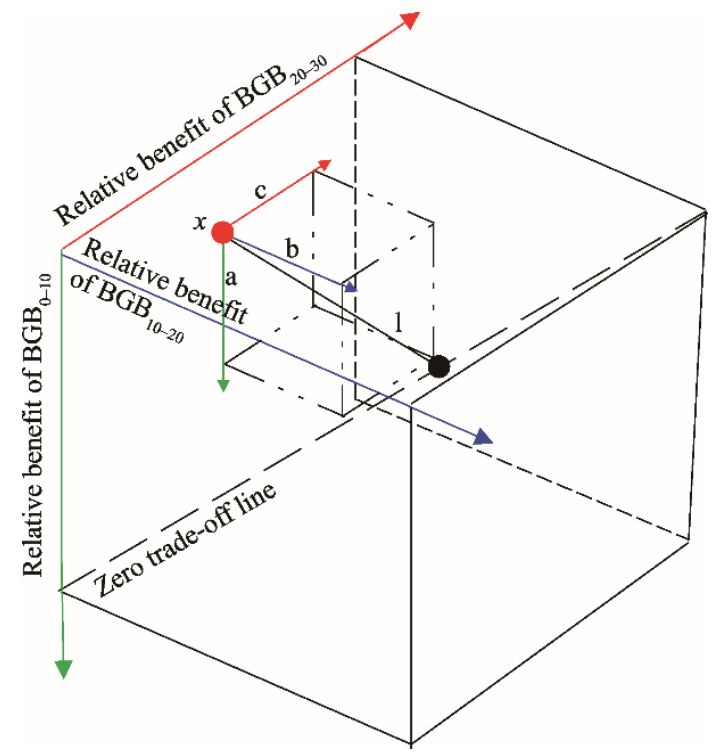

Fig. 2 Illustration of trade-offs among objective belowground biomass (BGB) values in the three soil layers (0$10,10-20$, and $20-30 \mathrm{~cm})$. The zero trade-off line represents that the benefits of BGB in each layer are equal. $\mathrm{BGB}_{0-10}, \mathrm{BGB}_{10-20}$, and $\mathrm{BGB}_{20-30}$ represent the $\mathrm{BGB}$ in the 0-10, 10-20, and 20-30 cm soil layers, respectively.

The differences in the soil properties in different soil layers along the degradation gradients were calculated by using SPSS 19.0 software (SPSS Inc., Chicago, IL, USA) to determine the one-way analysis of variance. We used linear piecewise quantile regression analysis and linear regression in SigmaPlot for Windows, version 10.0 (Systat Software, Inc., Chicago, IL, USA; Windows version 14.0) to visualize the changes in the AGB of graminoids and forbs along the degradation gradients, respectively. The ggplot2 and corrgram packages in $\mathrm{R}$ version 3.3 .2 ( $\mathrm{R}$ Core Team, 2016), were employed to explore the variation in the BGB trade-off values among the three soil layers along the degradation gradients and to determine the correlations among the BGB trade-off values, soil variables, and plant community structure, respectively.

\section{Results}

\subsection{Changes in soil characteristics along the degradation gradients}

SOC, STN, STP, SAN, SCOM, and SWC decreased gradually with increasing degradation degree, whereas no significant changes were found in SAP and SBD (Table 2). Most soil components such as SOC, STN, SAN, and SAP were significantly higher in the uppermost soil layer than in the subsoil layers. Similar patterns were found for SWC in the first and second degradation gradients (Table 2). 


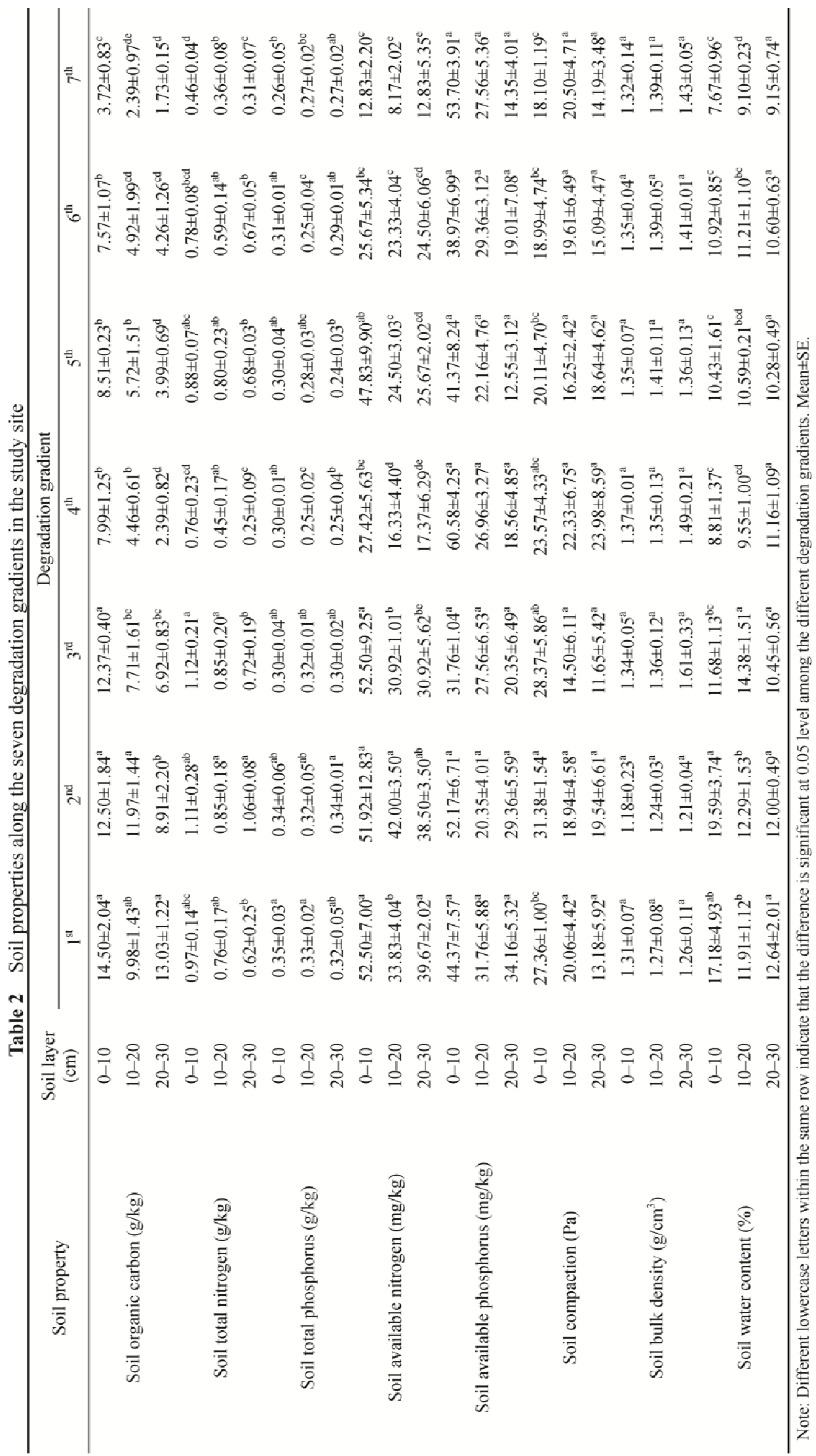




\subsection{Variations in plant aboveground biomass (AGB) and belowground biomass (BGB) along the degradation gradients}

With increasing degradation degree, the AGB of graminoids decreased dramatically until the $4^{\text {th }}$ degradation gradient and then decreased slowly, whereas the AGB of forbs changed little (Fig. 3). The graminoids clearly had a higher AGB than the forbs in the first degradation gradient, whereas the latter accounted for most of the AGB after the fourth degradation gradient.

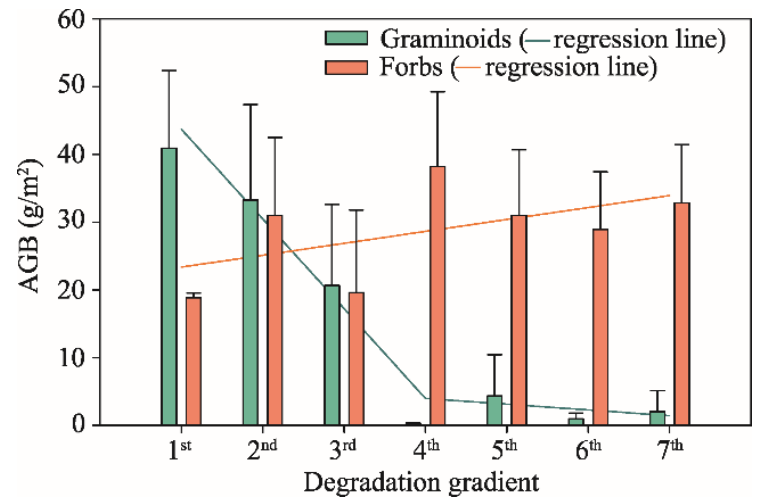

Fig. 3 Changes in aboveground biomass (AGB) of graminoids and forbs along the seven degradation gradients. Information on the seven degradation gradients is shown in Table 1.

The BGB clearly decreased along the degradation gradients. The value in the $0-10 \mathrm{~cm}$ soil layer $\left(\mathrm{BGB}_{0-10}\right)$ decreased dramatically with increasing degradation degree (Fig. 4). By contrast, the $\mathrm{BGB}$ in the $10-20 \mathrm{~cm}$ soil layer $\left(\mathrm{BGB}_{10-20}\right)$ remained virtually unchanged along the degradation gradients. The $\mathrm{BGB}$ in the $20-30 \mathrm{~cm}$ soil layer $\left(\mathrm{BGB}_{20-30}\right)$ tended to first decrease and then increase along the degradation gradients. $\mathrm{BGB}_{20-30}$ was similar to $\mathrm{BGB}_{10-20}$ but was clearly lower than $\mathrm{BGB}_{0-10}$ in most of the degradation gradients, with the exception of the $7^{\text {th }}$ gradient (Fig. 4).

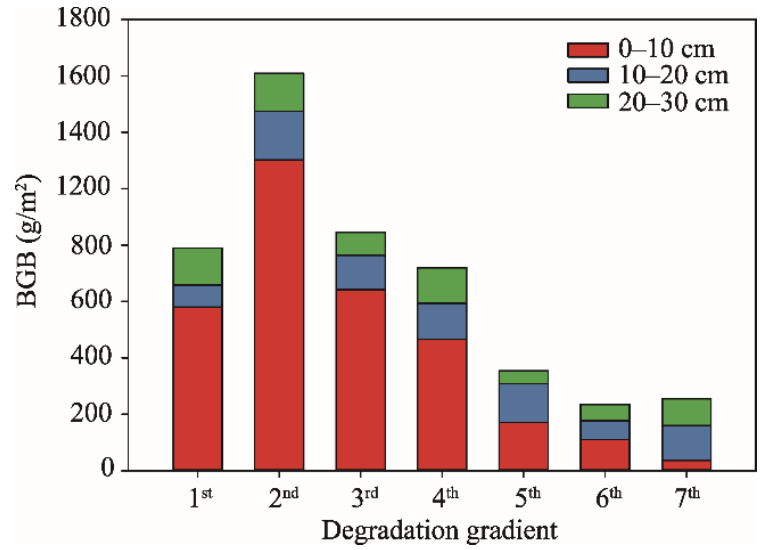

Fig. 4 Changes of belowground biomass (BGB) in the three soil layers $(0-10,10-20$, and 20-30 cm) along the seven degradation gradients

\subsection{Relationships among the BGB and soil and plant characteristics}

Figure 5 shows the variations in trade-off values of BGB in the three soil layers $(0-10,10-20$, and $20-30 \mathrm{~cm}$ ) along the degradation gradients. As shown in Figure 5, the trade-off value of $\mathrm{BGB}_{0-10}$ decreased remarkably with increasing degradation degree $\left(R^{2}=0.71, P<0.05\right)$. In the $0-10$ $\mathrm{cm}$ soil layer, the trade-off value of $\mathrm{BGB}_{0-10}$ exhibited significant positive correlations with $\mathrm{SWC}$ $\left(R^{2}=0.82\right)$, SCOM $\left(R^{2}=0.93\right)$, SOC $\left(R^{2}=0.77\right)$, STN $\left(R^{2}=0.76\right)$, STP $\left(R^{2}=0.69\right)$, and SAN $\left(R^{2}=0.69\right)$, and also with the ratio of $\mathrm{AGB}$ of graminoids to that of forbs (i.e., $\mathrm{AGB}(\mathrm{G} / \mathrm{F})$; 
$\left.R^{2}=0.66\right)$; however, it was negatively correlated with $\operatorname{SBD}\left(R^{2}=0.72\right)$ at the $95 \%$ confidence level (Fig. 6).

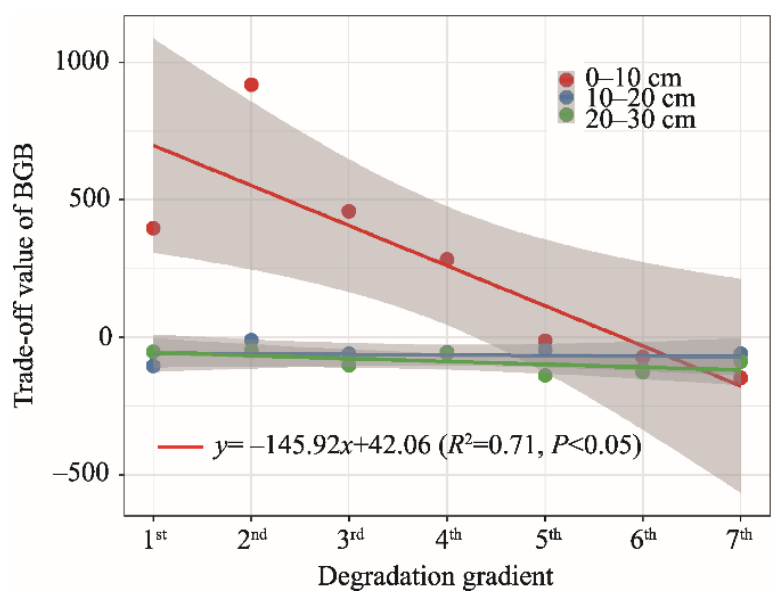

Fig. 5 Changes in trade-off values of BGB in the three soil layers $(0-10,10-20$, and 20-30 cm) along the seven degradation gradients. The gray area represents $95 \%$ confidence intervals.

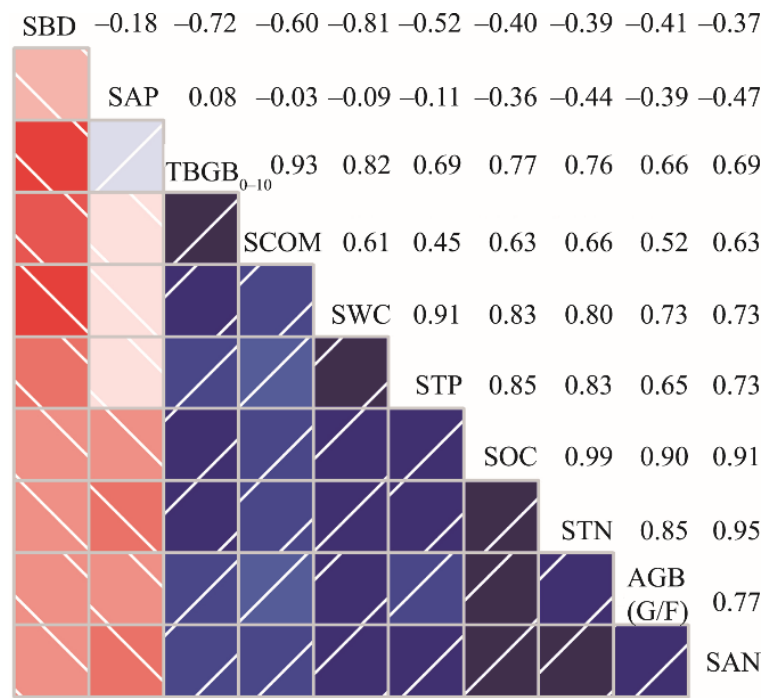

Fig. 6 Correlations among the trade-off value of $B G B$ in the $0-10 \mathrm{~cm}$ soil layer $\left(\mathrm{BGB}_{0-10}\right)$, topsoil physical-chemical properties, and plant community structure. SBD, soil bulk density; SAP, soil available phosphorus; SCOM, soil compaction; SWC, soil water content; STP, soil total phosphorus; SOC, soil organic carbon; STN, soil total nitrogen; AGB(G/F), the ratio of AGB of graminoids to that of forbs; SAN, soil available nitrogen. The color depth represents correlated strength, that is, a deep color suggests a strong correlation. Blue and red represent positive and negative correlations, respectively.

\section{Discussion}

\subsection{Variations of soil properties along the degradation gradients}

In agreement with previous studies showing that degradation resulted in considerable nutrient loss, which then accelerated degradation (Wen et al., 2013; Pan et al., 2017; Zhang et al., 2019), our results indicated that soil nutrients such as SOC, STN, STP, and SAN dramatically decreased with increasing degradation degree (Table 2). These findings could be attributed to the following factors. First, the degradation-induced reductions in vegetation biomass and coverage not only decrease the soil organic matter (SOM) input (Wang et al., 2009), but also enhance water and soil 
erosion, resulting in nutrient losses (Zhu et al., 2011; Dlamini et al., 2014). Second, changes in the microenvironment (e.g., SWC and SBD) along the degradation gradients increase the dissolution of SOM (Wang et al., 2008). Third, the degradation-induced turnover of species composition, for example, the ongoing replacement of grasses by ruderal species during grassland degradation, can affect the fixed soil C content (Wu et al., 2014; Han et al., 2018). Finally, changes in litter can have important effects on the variation of SOC (Mehta et al., 2013) and STN (Che et al., 2018). Specifically, degradation reduces the $\mathrm{C}$ and nitrogen $(\mathrm{N})$ storage by changing the quantity and quality of litter input to the soil (Sun et al., 2018a).

In this study, SWC decreased gradually with increasing degradation degree (Table 2), in agreement with numerous studies (Wei et al., 2010; Yi et al., 2012). The reason might be the negative effects of retrogression on the soil water-holding capacity (Fu et al., 2015) and an increase in evaporation owing to strong radiation due to degradation-induced plant cover reduction (Wang et al., 2009). Additionally, the decrease in SCOM with increasing degradation degree indicates that degradation causes the soil to be less cohesive by reducing the clay content and increasing the silt content (Yi et al., 2012). Notably, most of the soil physical-chemical properties were more vulnerable to degradation in the upper soil layer $(0-10 \mathrm{~cm})$ than in the subsoil layers (10-20 and 20-30 cm) (Table 1). Other works have reported similar behavior (Bardgett et al., 2005; Pan et al., 2017), which indicates that the impacts of degradation on the soil characteristics appear primarily in the upper soil layer. The reason is probably that degradation-induced decreases in vegetation cover and root grasp directly expose the surface soil to wind, rainfall, and surface flow (Pan et al., 2017).

\subsection{Effects of habitat and plant community structure on the dynamics of BGB distribution patterns}

We found that the BGB distribution was depth-dependent, with more than $50 \%$ concentrated in the $0-10 \mathrm{~cm}$ soil layer, except in extremely degraded grasslands (Fig. 4). This agrees overall with the pattern reported by $\mathrm{Li}$ et al. (2011) in the alpine grassland on the Tibetan Plateau, which is higher than the values reported in Inner Mongolia of China (47\%; Ma et al., 2008) and temperate zone grasslands worldwide (44\%; Jackson et al., 1996). The unique environmental conditions on the Tibetan Plateau, such as high soil rigidity and permafrost, might contribute to the depth dependence (Li et al., 2011). Of most interest to our study, the trade-off value of BGB in the $0-10$ $\mathrm{cm}$ soil layer $\left(\mathrm{BGB}_{0-10}\right)$ decreased dramatically along the degradation gradients. This finding could be explained by a range of direct or indirect possible mechanisms.

The soil physical-chemical properties affect the changes in the vertical distribution of BGB. There is an apparent positive association between the trade-off value of $\mathrm{BGB}_{0-10}$ and SCOM in the topsoil (Fig. 6), which suggests that individual deeply rooted plants provide resilience against large gale-force winds in cohesionless soil (Vo and Johnson, 2001). Moreover, soil with higher SBD is generally less porous; consequently, root respiration and microbial activities, and thus root growth, are limited (Yan et al., 2018), which is reflected in the negative correlation between the trade-off value of $\mathrm{BGB}_{0-10}$ and $\mathrm{SBD}_{0-10}(\mathrm{SBD}$ in the $0-10 \mathrm{~cm}$ soil layer) (Fig. 6). Additionally, SWC, which is tightly linked to nutrient availability, plays an important role in plant physiological activities (e.g., transpiration) and strongly affects plant growth (Swift et al., 2004). The significant positive correlation between the trade-off value of $\mathrm{BGB}_{0-10}$ and $\mathrm{SWC}_{0-10}(\mathrm{SWC}$ in the $0-10 \mathrm{~cm}$ soil layer) in our study (Fig. 6) indicated that deeper-rooted plants could use water from the subsoil when soil water in the upper soil decreased dramatically with increasing degradation degree (Hu et al., 2013).

Plants in infertile soil produce deep root systems to access nutrients from deeper soil layers (Wang et al., 2006; Han et al., 2011). In this study, we found significant positive correlations of the trade-off value of $\mathrm{BGB}_{0-10}$ with SOC, STN, STP, and SAN in the 0-10 cm soil layer (Fig. 6). Soil nutrients play important roles in multiple plant physiological activities: SOM provides energy for heterotrophic N-fixing microbes and further facilitates plant $\mathrm{N}$ fixation (Reed et al., 2011; Zheng et al., 2019); soil $\mathrm{N}$ has important effects on the leaf $\mathrm{N}$ and plant photosynthesis (Yue et al., 2019); low soil P can greatly limit plant growth and functioning (Quesada et al., 2009; 
Sun et al., 2019b). Consequently, soil nutrient changes can result in species turnover by affecting plant facilitation and competitive exclusion (Marriott et al., 2002; Guo, 2003).

Dynamics in the plant community structure directly affect the BGB vertical distribution patterns. Our results showed a dramatic decrease in AGB of graminoids and a slight increase in AGB of forbs with increasing degradation degree (Fig. 3). This finding suggests that plant communities tend to shift from graminoids to forbs after degradation occurs, showing successive vegetation reversal with the degradation of the plant community structure (Wang et al., 2009; Wu et al., 2009). This result is mainly because that the main cause of grassland degradation in our study site is free grazing, and selective foraging decreases the proportion of palatable graminoids. Moreover, forbs show a stronger competitive capacity than graminoids in the increasingly hostile environment resulting from increasing degradation degree (Sun et al., 2009; Han et al., 2011). Graminoids have shallow roots that extend horizontally in the surface soil, whereas forbs produce deep axial roots (Wang et al., 2004), which contribute directly to the reduction in the root biomass in the topsoil, as indicated by the significant positive correlation between the trade-off value of $\mathrm{BGB}_{0-10}$ and $\mathrm{AGB}(\mathrm{G} / \mathrm{F})$ (Fig. 6).

\section{Conclusions}

In the current study, an alpine meadow with sequential degrees of degradation at the Zoige Plateau was selected as a typical degraded grassland to analyze the variations in plant BGB distribution under degradation. The trade-off value of BGB in the soil layer of $0-10 \mathrm{~cm}$ clearly decreased with increasing degradation degree and exhibited significant positive correlations with SWC, SCOM, SOC, STN, and STP. Our findings suggest that alpine grassland degradation dramatically reduces belowground net primary production in the topsoil owing to degradation-induced deterioration of soil conditions and changes in the plant community structure. These results can provide valuable information for scientific assessment of the effects of degradation on the soil $\mathrm{C}$ pool distribution in alpine meadows on the Tibetan Plateau and similar areas worldwide. Larger-scale transect surveys should be used in future studies to further explore the general response of root biomass distribution to grassland degradation.

\section{Acknowledgements}

This study was funded by the State Key Research Development Program of China (2016YFC0501803, 2016YFC0501802), the China Postdoctoral Science Foundation (2017M620889), and the Second Tibetan Plateau Scientific Expedition and Research (2019QZKK0405). We appreciate the contributions of Dr. HOU Ge and Dr. MA Baibing in field survey and lab activities.

\section{References}

Bao S D. 2000. Soil and Agricultural Chemistry Analysis. Beijing: China Agriculture Press, 263-270. (in Chinese)

Bardgett R D, Bowman W D, Kaufmann R, et al. 2005. A temporal approach to linking aboveground and belowground ecology. Trends in Ecology \& Evolution, 20(11): 634-641.

Bradford J B, Damato A W. 2012. Recognizing trade-offs in multi-objective land management. Frontiers in Ecology and the Environment, 10(4): 210-216.

Che R X, Qin J L, Tahmasbian I, et al. 2018. Litter amendment rather than phosphorus can dramatically change inorganic nitrogen pools in a degraded grassland soil by affecting nitrogen-cycling microbes. Soil Biology and Biochemistry, 120(8): $145-152$.

Dlamini P, Chivenge P, Manson A, et al. 2014. Land degradation impact on soil organic carbon and nitrogen stocks of sub-tropical humid grasslands in South Africa. Geoderma, 235-236: 372-381.

Dong S K, Shang Z H, Gao J X, et al. 2020. Enhancing sustainability of grassland ecosystems through ecological restoration and grazing management in an era of climate change on Qinghai-Tibetan Plateau. Agriculture Ecosystem and Environment, 287: 106684, doi: 10.1016/j.agee.2019.106684.

Dukes J S, Chiariello N R, Cleland E E, et al. 2005. Responses of grassland production to single and multiple global environmental changes. PLoS Biology, 3(10): e319, doi: 10.1371/journal.pbio.0030319. 
Duran P, Thiergart T, Garridooter R, et al. 2018. Microbial interkingdom interactions in roots promote arabidopsis survival. Cell, 175(4): 973-983.

Fu T G, Chen H S, Zhang W, et al. 2015. Vertical distribution of soil saturated hydraulic conductivity and its influencing factors in a small karst catchment in Southwest China. Environmental Monitoring and Assessment, 187(3): 92-104.

Gląb T, Szewczyk W. 2014. Influence of simulated traffic and roots of turfgrass species on soil pore characteristics. Geoderma, 230-231: 221-228.

Gruber B D, Giehl R F H, Friedel S, et al. 2013. Plasticity of the arabidopsis root system under nutrient deficiencies. Plant Physiology, 163(1): 161-179.

Guo Q. 2003. Temporal species richness-biomass relationships along successional gradients. Journal of Vegetation Science, 14(1): 121-128.

Haichar F Z, Marol C, Berge O, et al. 2008. Plant host habitat and root exudates shape soil bacterial community structure. ISME Journal, 2(12): 1221-1230.

Han D M, Wang G Q, Xue B L, et al. 2018. Evaluation of semiarid grassland degradation in North China from multiple perspectives. Ecological Engineering, 112: 41-50.

Han L H, Shang Z H, Ren G H, et al. 2011. The response of plants and soil on black soil patch of the Qinghai-Tibetan Plateau to variation of bare-patch areas. Acta Prataculturae Sinica, 20(1): 4-9. (in Chinese)

Harris R B. 2010. Rangeland degradation on the Qinghai-Tibetan plateau: A review of the evidence of its magnitude and causes. Journal of Arid Environments, 74(1): 1-12.

Hewins D B, Fatemi F R, Adams B W, et al. 2015. Grazing, regional climate and soil biophysical impacts on microbial enzyme activity in grassland soil of western Canada. Pedobiologia, 58(5-6): 201-209.

Hortal S, Lozano Y M, Bastida F, et al. 2017. Plant-plant competition outcomes are modulated by plant effects on the soil bacterial community. Scientific Reports, 7(1): 1-9.

Hu J, Hopping K A, Bump J K, et al. 2013. Climate change and water use partitioning by different plant functional groups in a grassland on the Tibetan Plateau. PloS ONE, 8(9): e75503, doi: 10.1371/journal.pone.0075503.

Huo L L, Chen Z K, Zou Y C, et al. 2013. Effect of Zoige alpine wetland degradation on the density and fractions of soil organic carbon. Ecological Engineering, 51(1): 287-295.

Jackson R B, Canadell J, Ehleringer J R, et al. 1996. A global analysis of root distributions for terrestrial biomes. Oecologia, 108(3): 389-411.

Li P, Deng W, Zhang H, et al. 2019. Focus on economy or ecology? A three-dimensional trade-off based on ecological carrying capacity in Southwest China. Natural Resource Modeling, 32(2): e12201, doi: 10.1111/nrm.12201.

Li X J, Zhang X Z, Wu J S, et al. 2011. Root biomass distribution in alpine ecosystems of the northern Tibetan Plateau. Environmental Earth Sciences, 64(7): 1911-1919.

Li Y H, Luo T X, Lu Q J. 2008. Plant height as a simple predictor of the root to shoot ratio: Evidence from alpine grasslands on the Tibetan Plateau. Journal of Vegetation Science, 19(2): 245-252.

Li Y Y, Dong S K, Wen L, et al. 2013. The effects of fencing on carbon stocks in the degraded alpine grasslands of the Qinghai-Tibetan Plateau. Journal of Environmental Management, 128(20): 393-399.

Liu M, Zhang Z C, Sun J, et al. 2020a. Restoration efficiency of short-term grazing exclusion is the highest at the stage shifting from light to moderate degradation at Zoige, Tibetan Plateau. Ecological Indicators, 114: 106323, doi: 10.1016/j.ecolind.2020.106323.

Liu M, Zhang Z C, Sun J, et al. 2020b. One-year grazing exclusion remarkably restores degraded alpine meadow at Zoige, eastern Tibetan Plateau. Global Ecology and Conservation, 22: e00951, doi: 10.1016/j.gecco.2020.e00951.

Lynch J P, Brown K M. 2012. New roots for agriculture: Exploiting the root phenome. Philosophical Transactions of the Royal Society of London, 367(1595): 1598-1604.

Ma W H, Yang Y H, He J S, et al. 2008. Biomass and its relations with environmental factors in temperate zone grassland of Inner Mongolia. Science China-Life Sciences, 38(1): 84-92.

Ma Y S, Lang B N, Li Q Y, et al. 2002. Study on rehabilitating and rebuilding technologies for degenerated alpine meadow in the Changjiang and Yellow river source region. Pratacultural Science, 19(9): 1-5. (in Chinese)

Macinnis-Ng C M O, Fuentes S, O'Grady A P, et al. 2010. Root biomass distribution and soil properties of an open woodland on a duplex soil. Plant and Soil, 327: 377-388.

Marriott C A, Bolton G R, Barthram G T, et al. 2002. Early changes in species composition of upland sown grassland under extensive grazing management. Applied Vegetation Science, 5(1): 87-98.

Mehta N, Dinakaran J, Patel S, et al. 2013. Changes in litter decomposition and soil organic carbon in a reforested tropical deciduous cover (India). Ecological Research, 28(2): 239-248. 
Mokany K, Raison R, Prokushkin A. 2010. Critical analysis of root: shoot ratios in terrestrial biomes. Global Change Biology, 12(1): 84-96.

Olsen S R, Cole C V, Watanabe F S, et al. 1954. Estimation of available phosphorus in soils by extraction with sodium bicarbonate. USDA Circular, 93(9): 1-19.

Pan T, Hou S, Wu S H, et al. 2017. Variation of soil hydraulic properties with alpine grassland degradation in the eastern Tibetan Plateau. Hydrology and Earth System Sciences, 21(4): 2249-2261.

Piao S L, Tan K, Nan H J, et al. 2012. Impacts of climate and $\mathrm{CO}_{2}$ changes on the vegetation growth and carbon balance of Qinghai-Tibetan grasslands over the past five decades. Global and Planetary Change, 98: 73-80.

Pieterse C M, Zamioudis C, Berendsen R L, et al. 2014. Induced systemic resistance by beneficial microbes. Annual Review of Phytopathology, 52: 347-375.

Qin X J, Sun J, Wang X D. 2018. Plant coverage is more sensitive than species diversity in indicating the dynamics of the above-ground biomass along a precipitation gradient on the Tibetan Plateau. Ecological Indicators, 84(3): 507-514.

Qiu L P, Wei X R, Zhang X C, et al. 2013. Ecosystem carbon and nitrogen accumulation after grazing exclusion in semiarid grassland. PloS ONE, 8(1): e55433, doi: 10.1371/journal.pone.0055433.

Quesada C A, Lloyd J, Schwarz M, et al. 2009. Regional and large-scale patterns in Amazon forest structure and function are mediated by variations in soil physical and chemical properties. Biogeosciences Discussions, 6(2): 3993-4057.

R Core Team. 2016. R: A language and environment for statistical computing. R Foundation for Statistical Computing. Vienna, Austria.

Reed S C, Cleveland C C, Townsend A R. 2011. Functional ecology of free-Living nitrogen fixation: a contemporary perspective. Annual Review of Ecology, Evolution, and Systematics, 42(1): 489-512.

Rey T, Schornack S. 2013. Interactions of beneficial and detrimental root-colonizing filamentous microbes with plant hosts. Genome Biology, 14(6): 121-121.

Rodrigues R R, Pineda R P, Barney J N, et al. 2015. Plant invasions associated with change in root-zone microbial community structure and diversity. PloS ONE, 10(10): e0141424, doi: 10.1371/journal.pone.0141424.

Rodriguez M V, Bertiller M B, Bisigato A. 2007. Are fine roots of both shrubs and perennial grasses able to occupy the upper soil layer? A case study in the arid Patagonian Monte with non-seasonal precipitation. Plant and Soil, 300: $281-288$.

Rogers E D, Benfey P N. 2015. Regulation of plant root system architecture: Implications for crop advancement. Current Opinion in Biotechnology, 32: 93-98.

Silva P D, Adriana B F, Cezar J, et al. 2014. Soil structure and its influence on microbial biomass in different soil and crop management systems. Soil and Tillage Research, 142(1): 42-53.

Sun G, Luo P, Wu N, et al. 2009. Stellera chamaejasme L. increases soil N availability, turnover rates and microbial biomass in an alpine meadow ecosystem on the eastern Tibetan Plateau of China. Soil Biology and Biochemistry, 41(1): 86-91.

Sun J, Cheng G W, Li W P. 2013. Meta-analysis of relationships between environmental factors and aboveground biomass in the alpine grassland on the Tibetan Plateau. Biogeosciences, 10(3): 1707-1715.

Sun J, Wang X D, Cheng G W, et al. 2014. Effects of grazing regimes on plant traits and soil nutrients in an alpine steppe, northern Tibetan Plateau. PloS ONE, 9(9): e108821, doi: 10.1371/journal.pone.0108821.

Sun J, Wang H M. 2016. Soil nitrogen and carbon determine the trade-off of the above- and below-ground biomass across alpine grasslands, Tibetan Plateau. Ecological Indicators, 60(60): 1070-1076.

Sun J, Niu S L, Wang J N. 2018a. Divergent biomass partitioning to aboveground and belowground across forests in China. Journal of Plant Ecology, 11(3): 484-492.

Sun J, Ma B B, Lu X Y. 2018b. Grazing enhances soil nutrient effects: Trade-offs between aboveground and belowground biomass in alpine grasslands of the Tibetan Plateau. Land Degradation and Development, 29(2): 337-348.

Sun J, Zhang Z C, Dong S K. 2019a. Adaptive management of alpine grassland ecosystems over Tibetan Plateau. Pratacultural Science, 36(4): 933-938. (in Chinese)

Sun J, Liu B Y, You Y, et al. 2019b. Solar radiation regulates the leaf nitrogen and phosphorus stoichiometry across alpine meadows of the Tibetan Plateau. Agricultural and Forest Meteorology, 271: 92-101.

Swift M J, Izac A M N, Noordwijk M V. 2004. Biodiversity and ecosystem services in agricultural landscapes-are we asking the right questions? Agriculture Ecosystems \& Environment, 104(1): 113-134.

Tingey D T, Phillips D L, Johnson M G. 2010. Elevated $\mathrm{CO}_{2}$ and conifer roots: Effects on growth, life span and turnover. New Phytologist, 147(1): 87-103.

Verbon E H, Liberman L M. 2016. Beneficial microbes affect endogenous mechanisms controlling root development. Trends in Plant Science, 21(3): 218-229.

Vo S T K, Johnson E A. 2001. Alpine plant life: Functional plant ecology of high mountain ecosystems. In: Christian K. 
Mountain Research and Development, 21(2): 202.

Wang C T, Wang Q J, Long R J, et al. 2004. Changes in plant species diversity and productivity along an elevation gradient in an alpine meadow. Acta Phytoecologica Sinica, 28(2): 240-245. (in Chinese)

Wang C T, Long R J, Wang Q J, et al. 2009. Changes in plant diversity, biomass and soil C, in alpine meadows at different degradation stages in the headwater region of three rivers, China. Land Degradation and Development, 20(2): 187-198.

Wang G X, Li Y S, Wang Y B, et al. 2008. Effects of permafrost thawing on vegetation and soil carbon pool losses on the Qinghai-Tibet Plateau, China. Geoderma, 143(1-2): 143-152.

Wang W Y, Wang Q J, Wang H C. 2006. The effect of land management on plant community composition, species diversity, and productivity of alpine Kobersia steppe meadow. Ecological Research, 21(2): 181-187.

Wei Q, Wang F, Chen W Y, et al. 2010. Soil physical characteristics on different degraded alpine grasslands in Maqu County in upper Yellow River. Bulletin of Soil and Water Conservation, 30(5): 19-24. (in Chinese)

Wen L, Dong S K, Li Y Y, et al. 2013. The impact of land degradation on the C pools in alpine grasslands of the Qinghai-Tibet Plateau. Plant and Soil, 368: 329-340.

Wu G L, Du G Z, Liu Z H, et al. 2009. Effect of fencing and grazing on a Kobresia-dominated meadow in the Qinghai-Tibetan Plateau. Plant and Soil, 319: 115-126.

Wu G L, Ren G H, Dong Q M, et al. 2014. Above- and belowground response along degradation gradient in an alpine grassland of the Qinghai-Tibetan Plateau. Clean-Soil Air Water, 42(3): 319-323.

Wu Y B, Wu J, Deng Y C, et al. 2011. Comprehensive assessments of root biomass and production in a Kobresia humilis meadow on the Qinghai-Tibetan Plateau. Plant and Soil, 338: 497-510.

Yan Z, Bondlamberty B, Toddbrown K E O, et al. 2018. A moisture function of soil heterotrophic respiration that incorporates microscale processes. Nature Communications, 9(1): 2562, doi: 10.1038/s41467-018-04971-6.

Yang Y H, Fang J Y, Tang Y H, et al. 2008. Storage, patterns and controls of soil organic carbon in the Tibetan grasslands. Global Change Biology, 14(7): 1592-1599.

Yang Y H, Fang J Y, Ji C J, et al. 2009. Above- and belowground biomass allocation in Tibetan grasslands. Journal of Vegetation Science, 20(1): 177-184.

Yi X S, Li G S, Yin Y Y. 2012. The impacts of grassland vegetation degradation on soil hydrological and ecological effects in the source region of the Yellow River-A case study in Junmuchang region of Maqin country. Procedia Environmental Sciences, 13(3): 967-981.

Yue K, Peng Y, Fornara D A, et al. 2019. Responses of nitrogen concentrations and pools to multiple environmental change drivers: A meta-analysis across terrestrial ecosystems. Global Ecology and Biogeography, 28(5): 690-724.

Zhang B W, Cadotte M W, Chen S, et al. 2019. Plants alter their vertical root distribution rather than biomass allocation in response to changing precipitation. Ecology, 100(11): e02828, doi: 10.1002/ecy.2828.

Zhang Z C, Hou G, Liu M, et al. 2019. Degradation induces changes in the soil C:N:P stoichiometry of alpine steppe on the Tibetan Plateau. Journal of Mountain Science, 16(10): 2348-2360.

Zheng D, Zhang Q S, Wu S H. 2000. Mountain geoecology and sustainable development of the Tibetan Plateau. Geojournal Library, 57(2): 203-204.

Zheng M, Chen H, Li D, et al. 2019. Substrate stoichiometry determines nitrogen fixation throughout succession in southern Chinese forests. Ecology Letters, 23(2): 336-347.

Zhu M Y, Tan S D, Dang H S, et al. 2011. Rare earth elements tracing the soil erosion processes on slope surface under natural rainfall. Journal of Environmental Radioactivity, 102(12): 1078-1084. 